\title{
Site and Regional Trend Analysis of Precipitation in Central Macedonia, Greece
}

\author{
Athanasios K. Margaritidis \\ Faculty of Agriculture, Forestry and Natural Environment, School of Agriculture, Department of Hydraulics, \\ Soil Science \& Agriculture Engineering, Thessaloniki, Greece \\ Email: athamargaritidis@windowslive.com
}

How to cite this paper: Margaritidis, A.K. (2021) Site and Regional Trend Analysis of Precipitation in Central Macedonia, Greece. Computational Water, Energy, and Environmental Engineering, 10, 49-70. https://doi.org/10.4236/cweee.2021.102004

Received: January 16, 2021

Accepted: April 13, 2021

Published: April 16, 2021

Copyright $\odot 2021$ by author(s) and Scientific Research Publishing Inc. This work is licensed under the Creative Commons Attribution International License (CC BY 4.0).

http://creativecommons.org/licenses/by/4.0/

(c) (i) Open Access

\begin{abstract}
The purpose of this paper is to investigate the trend of precipitation in Kilkis region (Greece) at the site and regional level in various time scales. At the site level, the precipitation trend was analyzed using three tests: 1) Mann-Kendall, 2) Sen's $T$ and 3) Spearman while the trend slope was estimated using the Sen's estimator. At a regional level, nonparametric spatial tests such as Regional Average Mann-Kendall (RAMK) and BECD's (Bootstrap Empirical Cumulative Distributions) were elaborated with and without the effect of cross correlation. The trend of precipitation was noticed generally downward at annual time scale and statistically significant at 5\% level of significance only in only one station. The results of the analysis of trends at the regional level showed in total the influence of cross correlation in the time series since the number of trends detected is reduced when cross correlation is preserved. Precipitation data from 12 stations were used. The study results benefit water resource management, drought mitigation, socio-economic development, and sustainable agricultural planning in the region.
\end{abstract}

\section{Keywords}

Sen's T Test, Bootstrap Test, Precipitation, Trend Analysis, Greece

\section{Introduction}

As global climate change may affect long-term precipitation patterns resulting in an increase in droughts and floods, the continuous variability of precipitation around the world deserves urgent attention [1]. According to Climate Change 2007 [2] for a future warmer climate, the current generation of models shows that maximum precipitation generally increases in tropical areas (monsoon regimes) and over the tropical Pacific, with general decreases in the subtropics and 
increases in high latitudes, hampering the general intensification of the global hydrological cycle. The average of water vapor, evaporation and precipitation worldwide, is expected to increase. However, for example in China while an annual upward trend is observed, significant seasonal variations occur in several regions [3] [4]. Furthermore [5], point out the necessity to pay more attention to the prevention and mitigation of drought events that may occur in spring and summer periods. The results of the trend of precipitation in spatial levels of climatic regions of Canada [6] seem to be respective with emergence of an upward trend in the average precipitation in the northern region and a downward trend in the south-west, statistically significant at $5 \%$ significance level.

In Europe, and especially in the Mediterranean area recent researches [7]-[14] have shown a reduction of annual precipitation. Precipitation levels in Greece fluctuate extremely abnormally, both spatially and temporally resulting in an uneven distribution of water resources availability. More specifically, the pattern of precipitation indicates severe changes between the western part of Greece (greater precipitation level) and the other regions of the country. Several studies concerning precipitation variability [15] [16] [17] [18] [19], for a large number of meteorological stations in Greece show a downward trend which in some areas appears to be statistically significant.

The aim of this paper is to study the variation of precipitation and trend analysis with non-parametric methods in both site and spatial level for various time scales using 12 rain stations distributed as uniformly as possible in the geographical wider area of Kilkis region (Greece). An additional goal of this study is to investigate whether the drop of Lake Doirani from 146.3 meters to 141.1 meters in 2002 [19], is due to a statistically significant drop in precipitation at station level (Nov. Dojran) or area or exogenous factors. It is also worth mentioning that the investigation of trends in the study area has not been the subject of research for this period (1973-2008) with so many stations and so many periods, while special reference should be made to the fact that from 2011 onwards, most of the rain gauges have stopped working. The precipitation is recorded by the automatic meteorological station in the area of Kilkis (2004-present) and by the corresponding one in the area of Doirani in the Greek territory. Since precipitation is the main component of agricultural water management in the study area, a better understanding of its behavior through trend analysis can contribute significantly to the estimation of water resource availability and the development of adequate irrigation practices and crop patterns.

\section{Materials and Methods}

\subsection{Study Area}

The study area is situated in Northern Greece including the Prefecture of Kilkis bordering in the north with F.Y.R.O.M. (Figure 1). The climate of the study area is characterized as dry and warm (semi-arid) with moderate annual precipitation. From a geomorphological point of view, the terrain of the Prefecture of 


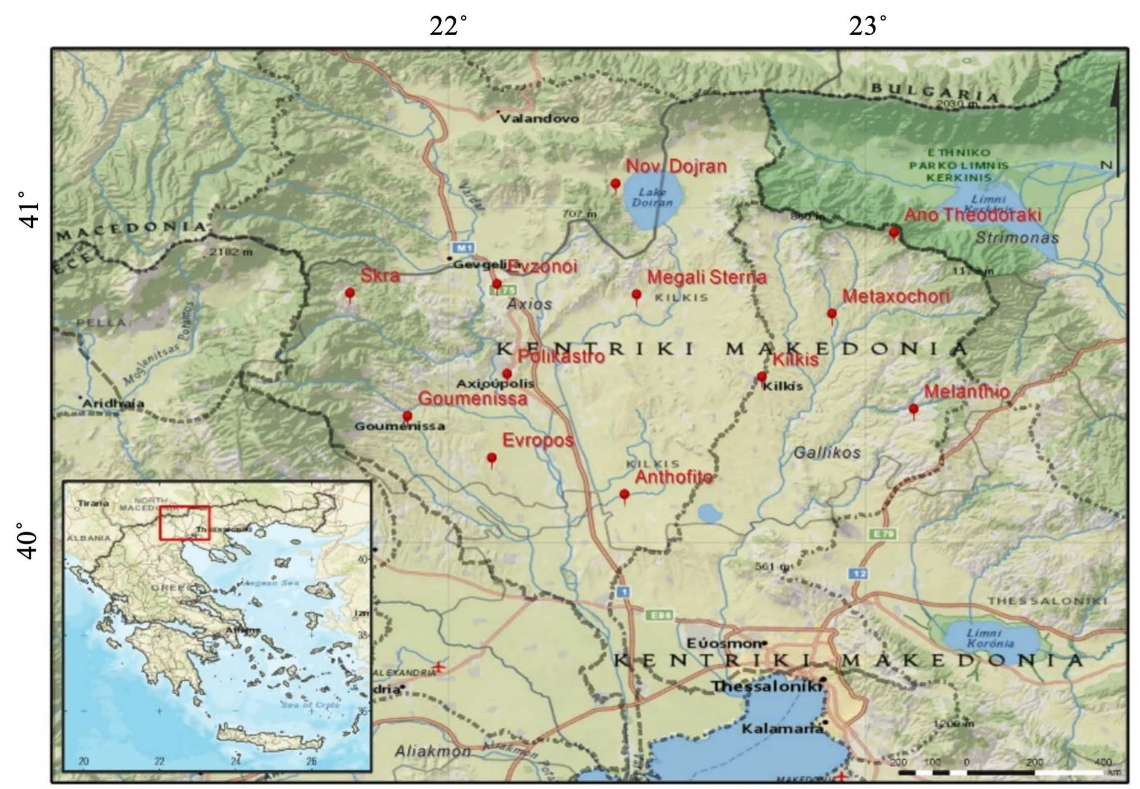

Figure 1. Study area, water basins and the distribution of selected stations (Basemap: Esri \& Open Street Map).

Kilkis is determined by the morphological characteristics of different hydrological basins (Figure 1). The basins, in which the study area is divided, are the basin of Lake Doiran (only part of the basin from the side of Greece), the Gallikos river basin, the basin of the Axios River and finally the Strimonas River basin (a part of Prefecture of Kilkis).

\subsection{Data}

The precipitation data used in this analysis were taken by 12 meteorological stations of the study area and cover the period 1973-2008 (36 years) (Table 1). In addition, these stations, at least in the Greek side, were consisted of pluviometers and rain gauges. As it can be noticed from Figure 1 and Table 1, the meteorological stations Ano Theodoraki, Metaxochori, Kilkis and Melanthio are located in the basin of the Gallikos river basin, the stations Evzonoi, Megali Sterna, Goumenissa, Polikastro, Skra, Evropos and Anthofito in the basin of the Axios River while the station Nov. Dojran (F.Y.R.O.M.) in the basin of Lake Doiran.

A preliminary examination of monthly values showed that the data of stations contain very little measurement gaps. Specifically, in the time series Nov. Dojran two missing values appeared in 2001 during the months of January and February, one value in the year 2007 in the same time series in July and one more in August 2008, which consist an almost zero percentage of the total value range (0.08\%).

In this paper, in order to fill in the time series, the weather station Polikastro was defined as a reference station, to fill in the missing values of the meteorological station Nov. Dojran. The reasons for this choice, are related to the reliability of the data (it is placed on the same altitude, it is located spatially closer to 
Table 1. Water basins, elevation above the sea level and mean annual precipitation ( $\mathrm{mm})$ for the stations of study area.

\begin{tabular}{cccc}
\hline Station & Hydrological Basin & Elevation $(\mathrm{m})$ & Mean Annual Precipitation $(\mathrm{mm})$ \\
\hline Nov. Dojran & Doiran Lake & 141 & 632.2 \\
Ano Theodoraki & Gallikos River & 480 & 433.6 \\
Metaxochori & Gallikos River & 277 & 521.6 \\
Kilkis & Gallikos River & 275 & 441.7 \\
Melanthio & Gallikos River & 490 & 587.6 \\
Anthofito & Axios River & 60 & 514.6 \\
Megali Sterna & Axios River & 125 & 541.3 \\
Evzonoi & Axios River & 90 & 566.2 \\
Polikastro & Axios River & 50 & 589.8 \\
Evropos & Axios River & 70 & 488.0 \\
Goumenissa & Axios River & 260 & 719.2 \\
Skra & Axios River & 540 & 736.8 \\
\hline
\end{tabular}

the Melanthio station) as well as with the better links between them (cross-correlation) of time series (Table 2). The method of filling gaps was the linear regression sum to zero (negative values) with the introduction of a random term [20].

\subsection{Methods}

After the successful analysis of the homogeneity [21], of the time series, an exploration of trends in precipitation is elaborated at site level using Mann-Kendall, Sen's T test, Sen's estimate of slope and Spearman and at regional level using Regional Average Mann-Kendall and Bootstrap tests (5\% significance level) in various time scales (Figure 2).

\section{Lag-1 Serial Correlation (pre-whitening)}

The approach of pre-whitening is one of the most common methods for calculating the serial correlation and its removal from the examined time series on condition that the calculated serial correlation is statistically significant at $5 \%$ level of significance (Table 3). The pre-whitening is performed as follows [22]:

$$
X_{t}^{\prime}=x_{t+1}-r_{1} \cdot x_{t}
$$

where $X_{t}^{\prime}$ is the pre-whitened time series for time interval $t, x_{t}$ and $x_{t+1}$ the initial time series for the time interval $t$ and $t+1$ respectively while $r_{1}$ is the lag-1 autocorrelation coefficient.

\section{Mann-Kendall test}

It consists one of the main and most widespread test non-parametric statistical tests in hydrometeorology. According to this test the null hypothesis $\mathrm{H}_{\mathrm{o}}$ and the alternative $\mathrm{H}_{1}$ are defined as follows:

$\mathrm{H}_{\mathrm{o}}$ : Observations with no monotonic trend 
Table 2. Cross-correlation coefficients between stations.

\begin{tabular}{ccccccccccccc}
\hline Station $\left(^{*}\right)$ & $\mathbf{1 .}$ & $\mathbf{2 .}$ & $\mathbf{3 .}$ & $\mathbf{4 .}$ & $\mathbf{5 .}$ & $\mathbf{6 .}$ & $\mathbf{7 .}$ & $\mathbf{8 .}$ & $\mathbf{9 .}$ & $\mathbf{1 0 .}$ & $\mathbf{1 1 .}$ & $\mathbf{1 2 .}$ \\
\hline $\mathbf{1 .}$ & 1 & 0.462 & 0.493 & 0.393 & 0.667 & 0.237 & 0.540 & 0.407 & 0.576 & 0.483 & 0.427 & 0.423 \\
$\mathbf{2 .}$ & 0.462 & 1 & 0.505 & 0.304 & 0.535 & 0.249 & 0.630 & 0.103 & 0.454 & 0.543 & 0.363 & 0.433 \\
$\mathbf{3 .}$ & 0.493 & 0.505 & 1 & 0.639 & 0.570 & 0.388 & 0.419 & 0.122 & 0.457 & 0.496 & 0.356 & 0.412 \\
$\mathbf{4 .}$ & 0.393 & 0.304 & 0.639 & 1 & 0.526 & 0.404 & 0.322 & 0.324 & 0.395 & 0.502 & 0.276 & 0.411 \\
$\mathbf{5 .}$ & 0.667 & 0.535 & 0.570 & 0.526 & 1 & 0.212 & 0.565 & 0.461 & 0.624 & 0.540 & 0.346 & 0.538 \\
$\mathbf{6 .}$ & 0.237 & 0.249 & 0.388 & 0.404 & 0.212 & 1 & 0.349 & 0.397 & 0.202 & 0.490 & 0.482 & 0.547 \\
$\mathbf{7 .}$ & 0.540 & 0.630 & 0.419 & 0.322 & 0.565 & 0.349 & 1 & 0.274 & 0.659 & 0.700 & 0.509 & 0.538 \\
$\mathbf{8 .}$ & 0.407 & 0.103 & 0.122 & 0.324 & 0.461 & 0.397 & 0.274 & 1 & 0.367 & 0.450 & 0.334 & 0.680 \\
$\mathbf{9 .}$ & 0.576 & 0.454 & 0.457 & 0.395 & 0.624 & 0.202 & 0.659 & 0.367 & 1 & 0.505 & 0.422 & 0.521 \\
$\mathbf{1 0 .}$ & 0.483 & 0.543 & 0.496 & 0.502 & 0.540 & 0.490 & 0.700 & 0.450 & 0.505 & 1 & 0.590 & 0.622 \\
$\mathbf{1 1 .}$ & 0.427 & 0.363 & 0.356 & 0.276 & 0.346 & 0.482 & 0.509 & 0.334 & 0.422 & 0.590 & 1 & 0.600 \\
$\mathbf{1 2 .}$ & 0.423 & 0.433 & 0.412 & 0.411 & 0.538 & 0.547 & 0.538 & 0.680 & 0.521 & 0.622 & 0.600 & 1 \\
\hline
\end{tabular}

*1. Nov. Dojran, 2. Ano Theodoraki, 3. Metaxochori, 4. Kilkis, 5. Melanthio, 6. Anthofito, 7. Megali Sterna, 8. Evzonoi, 9. Polikastro, 10. Evropos, 11. Goumenissa, 12. Skra.

Table 3. Time series with serial correlation at first lag, serial correlation levels at $5 \%$ level of significance and serial correlation values in all time periods of the study.

\begin{tabular}{cccc}
\hline Period & Lower bound & Upper bound & Stations with Lag-1 Serial Correlation \\
\hline Annual & -0.314 & 0.314 & $0.565^{4}, 0.564^{5}, 0.407^{8}, 0.377^{9}$ \\
Irrigation & -0.314 & 0.314 & $0.321^{4}, 0.393^{5}$ \\
Spring & -0.314 & 0.314 & $-0.330^{11}$ \\
Autumn & -0.314 & 0.314 & $0.368^{4}, 0.341^{8}$ \\
& & Months & \\
October & -0.314 & 0.314 & $0.323^{7}$ \\
December & -0.314 & 0.314 & $0.358^{5}$ \\
January & -0.314 & 0.314 & $0.333^{6}$ \\
March & -0.314 & 0.314 & $-0.328^{11}$ \\
May & -0.314 & 0.314 & $0.355^{4}$ \\
August & -0.314 & 0.314 & $0.383^{7}, 0.428^{10}, 0.367^{11}$ \\
\hline
\end{tabular}

1. Nov. Dojran. 2. Ano Theodoraki. 3. Metaxochori. 4. Kilkis. 5. Melanthio. 6. Anthofito. 7. Megali Sterna. 8. Evzonoi. 9. Polikastro. 10. Evropos. 11. Goumenissa. 12. Skra.

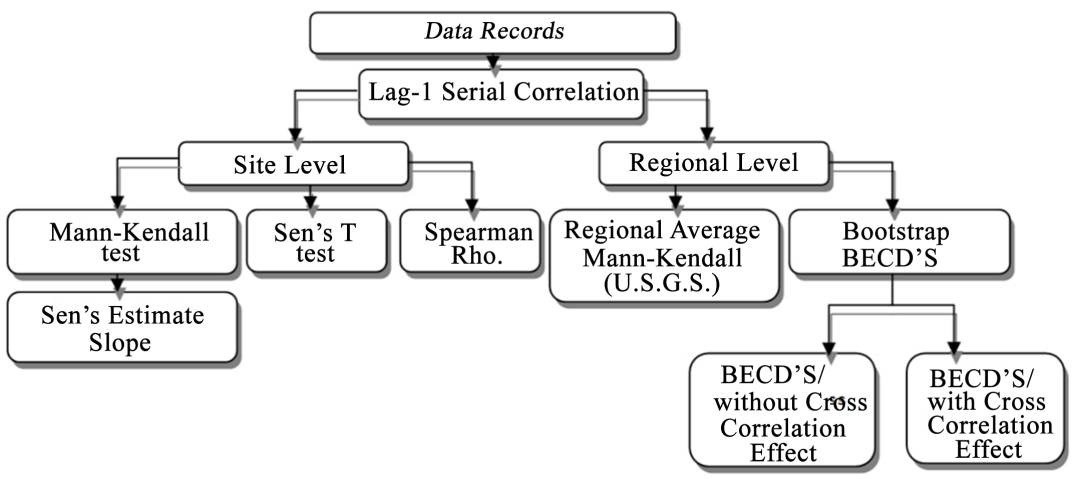

Figure 2. Trend analysis procedures-study methodology. 
$\mathrm{H}_{1}$ : Observations with monotonic trend (upward or downward)

The M-K statistic $S$ is calculated as follows [23] [24]:

$$
\begin{gathered}
S=\sum_{k=1}^{n-1} \sum_{j=k+1}^{n} \operatorname{sgn}\left(x_{j}-x_{k}\right) \\
\operatorname{sgn}\left(x_{j}-x_{k}\right)= \begin{cases}1 & \text { if }\left(x_{j}-x_{k}\right)>0 \\
0 & \text { if }\left(x_{j}-x_{k}\right)=0 \\
-1 & \text { if }\left(x_{j}-x_{k}\right)<0\end{cases}
\end{gathered}
$$

with $x_{j}$ and $x_{k}$ observations representing annual observations prices and $k, j \leq n$ and $k \# j$.

The variance of $S$ is calculated by the following formula:

$$
\operatorname{var} S=\frac{1}{18}\left[n(n-1)(2 n+5)-\sum_{t} t(t-1)(2 t+5)\right]
$$

where the notation $t$ refers to the extent of any given tie and $\sum_{t}$ states the summation over all ties.

Using the value of $S$, the standard normal test statistic $\mathrm{Z}$ is computed:

$$
Z= \begin{cases}\frac{S-1}{\sqrt{\operatorname{var} S}} & \text { if } S>0 \\ 0 & \text { if } S=0 \\ \frac{S+1}{\sqrt{\operatorname{var} S}} & \text { if } S<0\end{cases}
$$

In two-sided statistical test for the presence of a trend, the null hypothesis $\mathrm{H}_{\mathrm{o}}$ should be accepted if $|Z| \leq Z_{1-\left(\frac{\alpha}{2}\right)}$ at a predefined significance level $\alpha$ (e.g. $Z \leq$ 1.96 at $95 \%$ confidence interval).

Sen's-T test

It is classification method (ranked), which removes the seasonality from each time series summarizing the data at different seasons in order to produce a statistical trend value [25] [26]. This process is distributed free and it is not affected by seasonal variations [27]. The computational steps are:

- The average for the month $j$ is computed for a number of years $n$ :

$$
X_{j}=\sum_{i=1}^{n} \frac{X_{i j}}{n}
$$

and the average for the year $i$

$$
X_{i}=\sum_{j=1}^{12} \frac{X_{i j}}{12}
$$

- Then the average of each month is subtracted from each of the corresponding months in the $n$ years in order to remove seasonal effects e.g. $X_{i j}-X_{j}$ for $i=1,2, \cdots, n$ and $j=1,2, \cdots, 12$.

- The above differences $\left(X_{i j}-X_{j}\right)$ from 1 to $n \times m(n=$ number of years, $m=$ number of months) are ranked and a new table $\left(R_{i j}\right)$ is obtained, where $R_{i j}$ is the rank of $X_{i j}-X_{j}$. 
- The test statistic $\mathrm{T}$ is calculated by the following equation:

$$
T=\sqrt{\frac{12 m^{2}}{n(n+1) \sum_{i, j}\left(R_{i j}-R_{j}\right)^{2}}}\left[\sum_{i=1}^{n}\left(i-\frac{n+1}{2}\right)\left(R_{i}-\frac{n m+1}{2}\right)\right]
$$

For sample size $(n)$, the trend $T$ tends towards that of the standard normal distribution under the null hypothesis of non-existence of trend. The Sen's T test statistic is compared to the standard normal variate $Z$ in order to detect the trend existence.

\section{Sen's Estimator of Slope}

The Sen's estimator is used in those cases that can be detected the presence of a linear trend [17].

The estimate of the slope of the trend results from the median of the $N$ slopes $Q_{i}$ of data pairs:

$$
Q_{i}=\frac{x_{j}-x_{k}}{j-k}
$$

when $j>k, i=1,2, \cdots, N$.

The estimate of the slope of the trend of Sen is the median of $Q_{i}$ ranked from smallest to largest:

$$
Q= \begin{cases}Q_{\frac{N+1}{2}} & \text { for odd values of } N \\ \left.\frac{Q_{N}+Q_{\frac{N+2}{2}}}{2}\right] & \text { for even values of } N\end{cases}
$$

Regional Average Mann-Kendall (RAMK) test

In the case of spatial data observation, i.e. split into $(m)$ locations, test is applied to the data of each location, separating them essentially in $(m)$ sub-series, each of which represents a corresponding region [28] [29] [30]:

$$
\overline{S_{r}}=\frac{1}{m} \sum_{L=1}^{m} S_{L}
$$

where $\overline{S_{r}}$ is the regional average M-K statistic and $S_{L}$ is the M-K statistic for each $L$ station in the region.

The variance of $\overline{S_{r}}$ is calculated by the following formula:

$$
\operatorname{var}\left(\overline{S_{r}}\right)=\frac{1}{18 m}\left[n(n-1)(2 n+5)-\sum_{t} t(t-1)(2 t+5)\right]
$$

where the notation $t$ refers to the extent of any given tie and $\sum_{t}$ states the summation over all ties.

The standard normal variate is computed as follows:

$$
Z_{m}=\frac{\overline{S_{r}}}{\sqrt{\frac{\operatorname{var}\left(\overline{S_{r}}\right)}{m}}}
$$

The statistical significance of $Z_{m}$ is computed from the Cumulative Distri- 
bution Function of the standard normal variate.

\section{Regional Average Mann-Kendall Bootstrap (RAMK-B) test}

To find a general pattern of changes over a specific region, it is necessary to assess the field significance of trends in the region. Like the existence of serial correlation in time series, the presence of positive cross-correlation among sites in a region will result in an increased probability of rejecting the null hypothesis of no trend, while it might be actually true in some cases [28].

This study adopts a bootstrapping approach [30] [31] [32] that is similar in spirit to the method [28]. The approach is described as follows:

1) The selected calculation period or range of years, for example, [1973, $1974, \ldots, 2008]$ is resampled randomly with replacement. Then we can get a new set with different year order from the original one but with the same length, for instance, [1975, 1979, 1995, 1995, 2008].

2) Each site within a network has an observation value corresponding to a calendar year. By rearranging the observation values of each site of the network according to the new year set obtained in step (1), a new network can be obtained.

3) The M-K statistic (Equation (2)) at site $L$ in the bootstrapped network can be computed. The RAMK statistic can be calculated by equation (11).

4) By repeating steps (1)-(3) $N$ times (i.e. $N=4000$ ), $N$ values of the RAMK statistics can be obtained. Then the Bootstrap Empirical Cumulative Distribution (B.E.C.D.) of the RAMK statistic $\left(\overline{S_{r}}\right)$ can be obtained by ranking the $N$ values of the RAMK statistic in ascending order and assigning a non-exceedance probability using the Weibull plotting position formula as:

$$
P=\frac{r}{N+1}
$$

where $r$ is the rank of $\overline{S_{r}}$ in the bootstrap sample data according to the ascending order.

The probability value $\left(P_{o b s}\right)$ of the historical RAMK statistic can be obtained by comparing it with the bootstrap empirical cumulative distributions. The corresponding $P_{f}$ value is given by:

$$
P_{f}= \begin{cases}P_{o b s} & \text { for } P_{o b s} \leq 0.50 \\ 1-P_{o b s} & \text { for } P_{o b s}>0.50\end{cases}
$$

The field significance is obtained as follows: if $P_{f}$ is less than $\alpha$ (level of significance) then the trend is considered as field significant at the predefined $\alpha$ level ( $1-\alpha$ confidence level).

In the above procedure, if one directly resamples the sample data at a site rather than the year series as in steps (1) and (2), then a BECD without preserving cross-correlation structure of a network can be obtained.

\section{Results}

\subsection{Site Trend Analysis}

The precipitation data in all periods of study, for the 36 years, for the 12 stations 
of the study area, were investigated at site level.

In the annual observations, a statistically significant trend at a level of significant $5 \%$ by all trend tests, appeared only in Kilkis station, as depicted both in Figure 3 and in Table 4. Generally, for the whole study area, four stations had positive trends while the remaining eight negative ones but only one station showed a statistically significant downward trend in precipitation. Furthermore, in all cases (Table 5(a) and Table 5(b)), the results of Mann-Kendall [33] and Sen's T tests were successfully verified by Spearman's method.

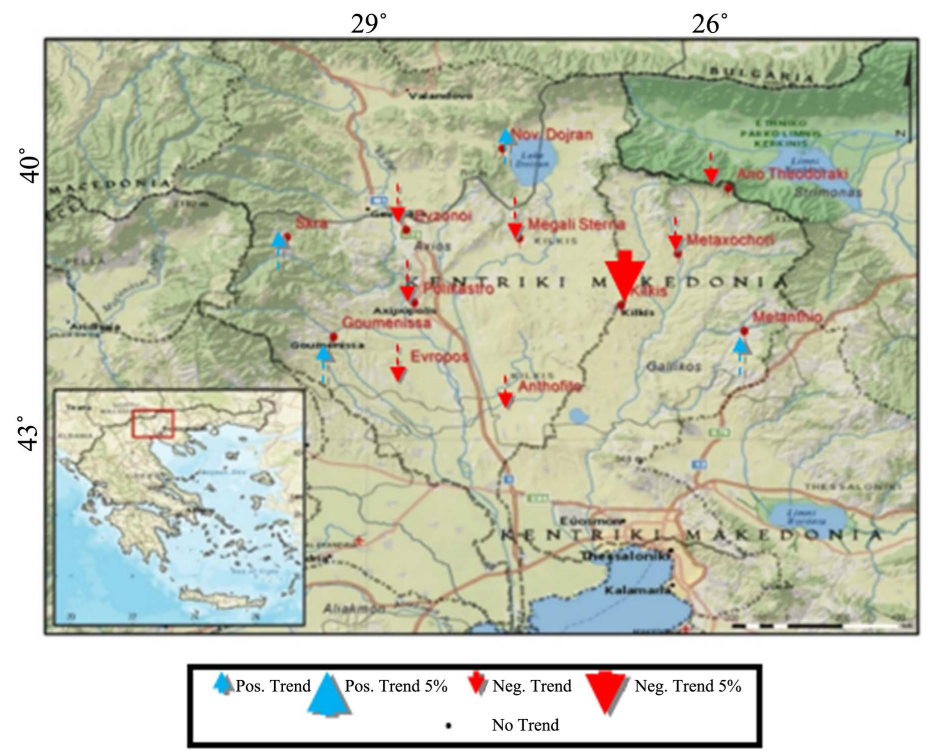

Figure 3. Annual trend results with non-parametric test Mann-Kendall at 12 stations in the study area.

Table 4. Trend results and slope estimation in the study area for annual time period.

\begin{tabular}{ccccc}
\hline Station & $\begin{array}{c}\text { M-K } \\
\text { Test Z }\end{array}$ & Sen-T & $\begin{array}{c}\text { Sen's } \\
\text { slope (mm/year) }\end{array}$ & $\begin{array}{c}\text { Spearman } \\
\text { p value }\end{array}$ \\
\hline Nov. Dojran & 0.59 & 0.769 & 1.306 & 0.450 \\
Ano Theodoraki & -0.63 & -0.628 & -1.351 & 0.536 \\
Metaxochori & -1.21 & -1.070 & -3.344 & 0.290 \\
Kilkis & $-1.99^{*}$ & $-\mathbf{2 . 0 1 2 ^ { * }}$ & $-3.647^{*}$ & $\mathbf{0 . 0 4 3 ^ { * }}$ \\
Melanthio & 0.27 & 0.362 & 0.572 & 0.724 \\
Anthofito & -0.83 & -1.002 & -2.316 & 0.322 \\
Megali Sterna & -0.37 & -0.396 & -0.993 & 0.697 \\
Evzonoi & -0.07 & 0.006 & -0.431 & 0.995 \\
Polikastro & -0.76 & -0.799 & -3.139 & 0.430 \\
Evropos & -1.24 & -1.332 & -2.534 & 0.186 \\
Goumenissa & 0.45 & 0.387 & 1.477 & 0.703 \\
Skra & 0.31 & 0.519 & 1.370 & 0.609 \\
\hline
\end{tabular}


Table 5. (a) Trend results and slope estimation in the study area for the irrigation period (May-September); (b) Trend results and slope estimation in the study area for the irrigation period (May-September).

(a)

\begin{tabular}{cccccc}
\hline Station & $\begin{array}{c}\text { Hydrological } \\
\text { Basin }\end{array}$ & $\begin{array}{c}\text { M-K } \\
\text { Test Z }\end{array}$ & Sen-T & $\begin{array}{c}\text { M-K } \\
\text { test Q }\end{array}$ & $\begin{array}{c}\text { Spearman } \\
\text { p value }\end{array}$ \\
\hline Nov. Dojran & Doiran Lake & 0.20 & 0.382 & 0.442 & 0.707 \\
Ano Theodoraki & Gallikos River & -0.56 & -0.509 & -0.698 & 0.617 \\
Metaxochori & Gallikos River & -0.76 & -0.671 & -0.963 & 0.509 \\
Kilkis & Gallikos River & -1.74 & -1.634 & -2.099 & 0.103 \\
Melanthio & Gallikos River & 0.95 & 0.810 & 1.843 & 0.424 \\
Anthofito & Axios River & -0.89 & -0.946 & -0.889 & 0.350 \\
\hline
\end{tabular}

(b)

\begin{tabular}{cccccc}
\hline Station & $\begin{array}{c}\text { Hydrological } \\
\text { Basin }\end{array}$ & $\begin{array}{c}\text { M-K } \\
\text { Test Z }\end{array}$ & Sen-T & $\begin{array}{c}\text { M-K } \\
\text { test Q }\end{array}$ & $\begin{array}{c}\text { Spearman } \\
\text { p value }\end{array}$ \\
\hline Megali Sterna & Axios River & 0.60 & 0.627 & 0.749 & 0.537 \\
Evzonoi & Axios River & 0.40 & 0.259 & 0.801 & 0.799 \\
Polikastro & Axios River & -0.80 & -0.894 & -1.409 & 0.378 \\
Evropos & Axios River & -0.82 & -0.869 & -1.331 & 0.391 \\
Goumenissa & Axios River & -0.20 & -0.263 & -0.191 & 0.797 \\
Skra & Axios River & 0.33 & 0.560 & 0.435 & 0.581 \\
\hline
\end{tabular}

As shown in Table 4, the Sen's Estimator of Slope, showed a negative value of slope trend $(-3.647 \mathrm{~mm} /$ period) at $5 \%$ significance level in Kilkis station (Figure 4). All results of the slope of the precipitation trend were also confirmed, as expected, by the results of the non-parametric tests Mann-Kendall, Spearman.

During the irrigation season (May-September) the trend detection is particularly important both for the rational crop irrigation and for the rotation of the crop. The water requirements of crops are directly linked to climate and specifically to precipitation and its trend in this area. An upward trend of precipitation occurred in Lake Doiran basin while the basin of Axios River showed both downward and upward trends (Table 5(a) and Table 5(b) and Figure 5). However, in the above-mentioned basins there are no statistically significant trends. The majority of stations of Gallikos river basin showed negative trends but only one (Kilkis) appeared to be statistically significant at $10 \%$ level.

Similar to the trend detections, were the results of trend slopes in the study area during the irrigation period (Table 5(a) and Table 5(b)). The most characteristic of all is the negative slope of the trend of Kilkis station which was found to be $-2.099 \mathrm{~mm} /$ period.

In four seasons analysis, as it can be seen from Figure 6, in the winter season mainly upward trends where observed while in spring downward ones in most stations. The summer showed only three upward trends while a statistically significant downward trend at 5\% significance level is identified only in the Kilkis 


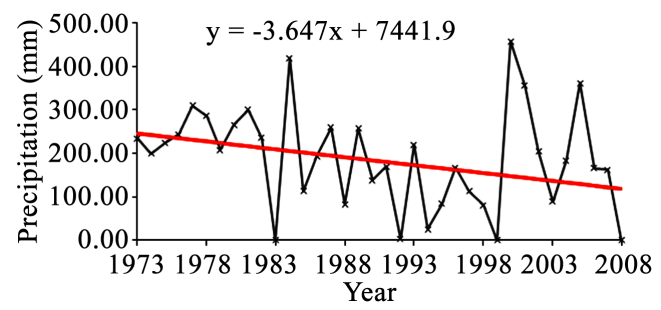

Figure 4. Sen's estimator of slope at Kilkis station (annual scale).
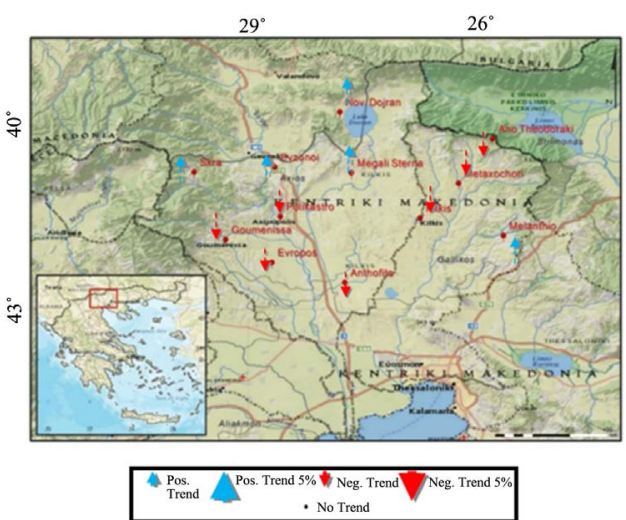

Figure 5. Trend results with non-parametric test Mann-Kendall at 12 stations in the study area during the irrigation period.
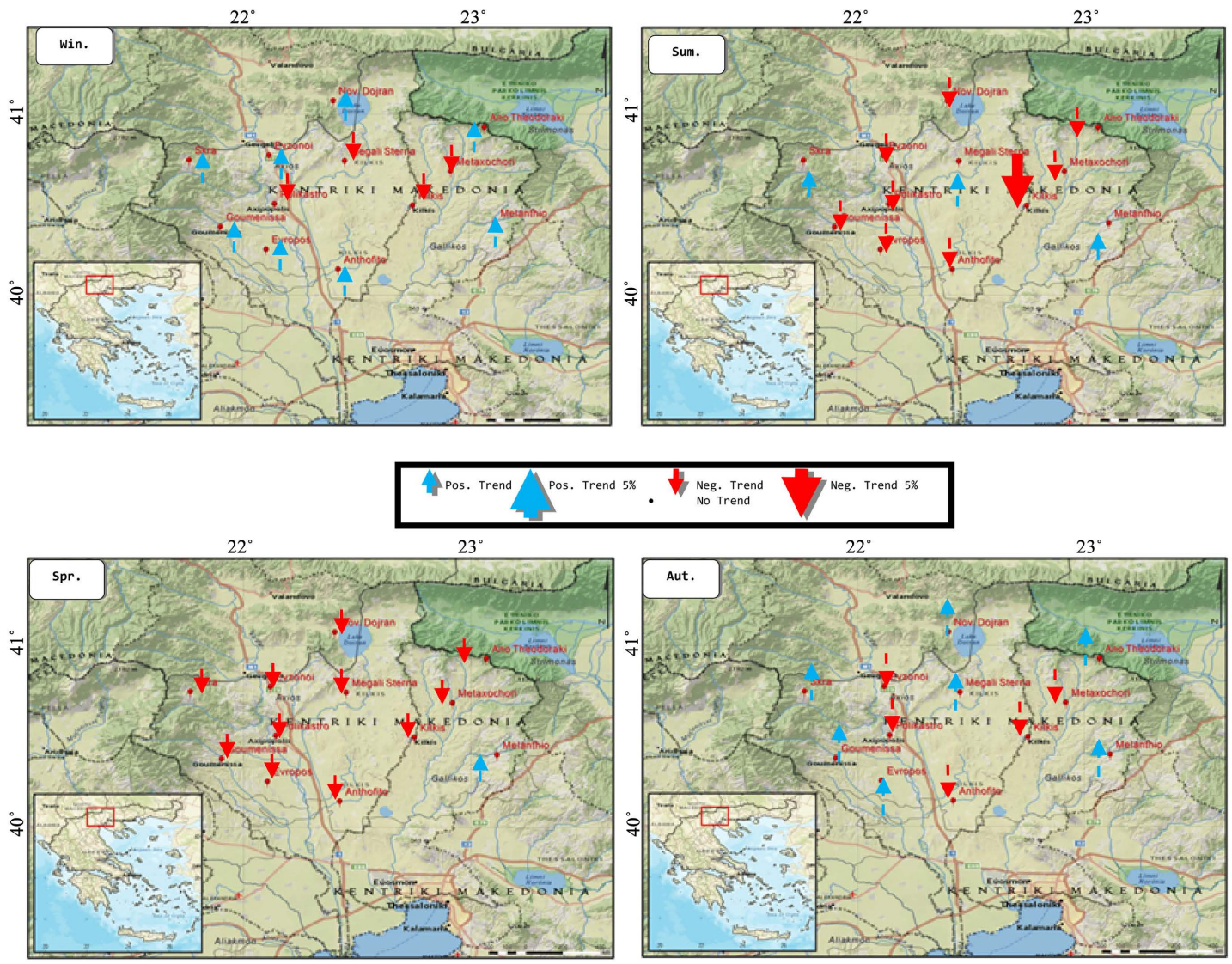

Figure 6. Seasonal trend results with non-parametric test Mann-Kendall at 12 stations in the study area. 
station (Figure 6). In autumn, both downward and upward not statistically significant trends occurred (Table 6).

Concerning the trend slopes of precipitation in seasonal period analysis, the statistically significant downward trend slope of Kilkis station was estimated as equal to $2.1 \mathrm{~mm} /$ season at a significance level of $5 \%$ as shown in Figure 7 and Table 7.

Table 6. Seasonal trend results of precipitation with Mann-Kendall, Spearman and Sen's-T tests in the study area.

\begin{tabular}{|c|c|c|c|c|c|c|c|c|c|c|c|c|}
\hline \multicolumn{13}{|c|}{ Mann-Kendall/Spearman/Sen-T } \\
\hline$(* *)$ & \multicolumn{3}{|c|}{1} & \multicolumn{3}{|c|}{2} & \multicolumn{3}{|c|}{3} & \multicolumn{3}{|c|}{4} \\
\hline \multirow{2}{*}{$\begin{array}{l}\text { Total Precip. } \\
(1973-2008)\end{array}$} & $\mathrm{M}-\mathrm{K}$ & Spearman & \multirow{2}{*}{ Sen-T } & $\mathrm{M}-\mathrm{K}$ & Spearman & \multirow{2}{*}{ Sen-T } & $\mathrm{M}-\mathrm{K}$ & Spearman & \multirow{2}{*}{ Sen-T } & $\mathrm{M}-\mathrm{K}$ & Spearman & \multirow{2}{*}{ Sen-T } \\
\hline & Test Z & $\mathrm{p}$ value & & Test Z & $\mathrm{p}$ value & & Test Z & $\mathrm{p}$ value & & Test Z & $p$ value & \\
\hline Winter & 1.10 & 0.243 & 1.178 & 0.10 & 0.865 & 0.184 & -1.05 & 0.253 & -1.154 & -1.13 & 0.269 & -1.116 \\
\hline Spring & -0.42 & 0.569 & -0.579 & -1.51 & 0.117 & -1.575 & -0.68 & 0.494 & -0.694 & -1.40 & 0.135 & -1.500 \\
\hline Summer & -0.15 & 0.962 & -0.049 & -0.10 & 0.889 & -0.143 & -1.19 & 0.262 & -1.133 & $-2.15^{*}$ & $0.037^{*}$ & $-2.067^{*}$ \\
\hline Autumn & 0.40 & 0.547 & 0.611 & 1.09 & 0.385 & 0.880 & -0.25 & 0.906 & -0.120 & -1.05 & 0.350 & -0.946 \\
\hline$(* *)$ & & 5 & & & 6 & & & 7 & & & 8 & \\
\hline Winter & 0.59 & 0.376 & 0.895 & 0.53 & 0.535 & 0.629 & -0.31 & 0.969 & 0.040 & 1.62 & 0.074 & 1.783 \\
\hline Spring & 0.90 & 0.278 & 1.095 & -1.01 & 0.295 & -1.059 & -0.68 & 0.455 & -0.758 & -1.31 & 0.198 & -1.297 \\
\hline Summer & 1.62 & 0.128 & 1.529 & -1.32 & 0.155 & -1.430 & 0.19 & 0.974 & 0.033 & -0.19 & 0.895 & -0.135 \\
\hline Autumn & 1.44 & 0.151 & 1.443 & -0.59 & 0.556 & -0.599 & 0.72 & 0.502 & 0.681 & -0.10 & 0.851 & -0.192 \\
\hline$(* *)$ & & 9 & & & 10 & & & 11 & & & 12 & \\
\hline Winter & -0.37 & 0.693 & -0.402 & 0.16 & 0.589 & 0.549 & 0.42 & 0.548 & 0.609 & 0.91 & 0.329 & 0.987 \\
\hline Spring & -0.56 & 0.575 & -0.570 & -0.89 & 0.330 & -0.987 & -1.40 & 0.216 & -1.249 & -0.84 & 0.399 & -0.855 \\
\hline Summer & -0.56 & 0.477 & -0.722 & -1.55 & 0.127 & -1.531 & -0.53 & 0.534 & -0.632 & 0.18 & 0.758 & 0.313 \\
\hline Autumn & -0.86 & 0.302 & -1.043 & 0.16 & 0.738 & 0.340 & 0.42 & 0.707 & 0.382 & 0.01 & 0.931 & 0.088 \\
\hline
\end{tabular}

${ }^{*}$ Statistically significant at the $5 \%$ level of significance. ${ }^{*}$ 1. Nov. Dojran. 2. Ano Theodoraki. 3. Metaxochori. 4. Kilkis. 5. Melanthio. 6. Anthofito. 7. Megali Sterna. 8. Evzonoi. 9. Polikastro. 10. Evropos. 11. Goumenissa. 12. Skra.

Table 7. Seasonal trend results of the slope of the precipitation trend in the study area.

\begin{tabular}{|c|c|c|c|c|c|c|c|c|c|c|c|c|}
\hline \multicolumn{13}{|c|}{ Sen's Estimate Slope (mm/period) } \\
\hline$(* *)$ & 1. & 2. & 3. & 4. & 5. & 6. & 7. & 8. & 9. & 10. & 11. & 12. \\
\hline $\begin{array}{c}\text { Precipitation } \\
(1973-2008)\end{array}$ & $\begin{array}{c}\text { M-K } \\
\text { Test Q }\end{array}$ & $\begin{array}{c}\text { M-K } \\
\text { Test Q }\end{array}$ & $\begin{array}{c}\text { M-K } \\
\text { Test Q }\end{array}$ & $\begin{array}{c}\text { M-K } \\
\text { Test Q }\end{array}$ & $\begin{array}{c}\text { M-K } \\
\text { Test Q }\end{array}$ & $\begin{array}{c}\text { M-K } \\
\text { Test Q }\end{array}$ & $\begin{array}{c}\text { M-K } \\
\text { Test Q }\end{array}$ & $\begin{array}{c}\text { M-K } \\
\text { Test Q }\end{array}$ & $\begin{array}{c}\text { M-K } \\
\text { Test Q }\end{array}$ & $\begin{array}{c}\text { M-K } \\
\text { Test Q }\end{array}$ & $\begin{array}{c}\text { M-K } \\
\text { Test Q }\end{array}$ & $\begin{array}{c}\text { M-K } \\
\text { Test Q }\end{array}$ \\
\hline Winter & 1.166 & 0.134 & -1.051 & -0.738 & 0.802 & 0.601 & -0.209 & 2.538 & -0.460 & 0.220 & 0.761 & 1.771 \\
\hline Spring & -0.461 & -1.130 & -0.546 & -1.124 & 0.844 & -0.752 & -0.605 & -1.300 & -0.371 & -0.816 & -1.906 & -1.118 \\
\hline Summer & -0.153 & -0.101 & -1.457 & $-2.09 *$ & 2.102 & -1.241 & 0.288 & -0.224 & -0.438 & -1.892 & -0.689 & 0.089 \\
\hline Autumn & 0.666 & 0.897 & -0.345 & -0.897 & 1.795 & -0.978 & 0.535 & -0.186 & -1.191 & 0.322 & 1.066 & 0.092 \\
\hline
\end{tabular}

* Statistically significant at the $5 \%$ level of significance. ${ }^{*} 1$. Nov. Dojran. 2. Ano Theodoraki. 3. Metaxochori. 4. Kilkis. 5. Melanthio. 6. Anthofito. 7. Megali Sterna. 8. Evzonoi. 9. Polikastro. 10. Evropos. 11. Goumenissa. 12. Skra. 


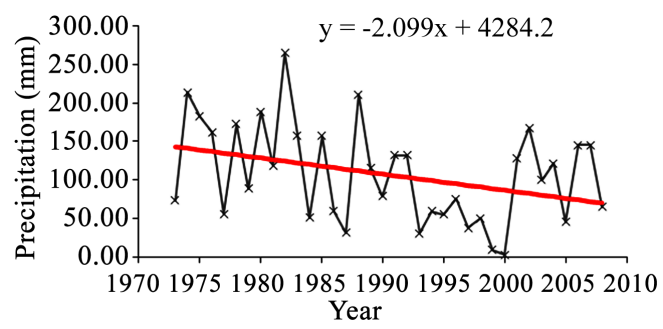

Figure 7. Sen's estimator of slope at Kilkis station (summer period).

On a monthly basis, the trend in the examined stations has appeared in several time series statistically significant at 5\% significance level. In Table 8 the trend sign results of the non-parametric Mann-Kendall, Sen-T kaı Spearman Rho tests are presented. October showed an equal number of negative and positive trends. November was identified as a month with a negative trend of precipitation in all stations except Melanthio and Skra station which showed upward trends. The Anthofito station showed a statistically significant positive slope trend at a 5\% level of significance. The month of December is characterized as a month of positive trend precipitation but only Skra station was identified statistically significant at a significance level of 5\%. January showed both positive and negative trends. February showed mostly downward trends while not statistically significant. Negative and not statistically significant were the trends in all stations in March as well. In April, both negative and positive trends which were also not statistically significant were calculated.

In May, only two stations presented upward trend but non-statistically significant while the remaining stations showed downward trend with only the Ano Theodoraki station identified as statistically significant at $5 \%$ level of significance. No prevailing trend direction could characterize the months of June and July. In August, two statistically significant trends were identified in stations Evropos and Kilkis at significance level of 5\%. Finally, during the last month of hydrological year (September) Megali Sterna, Melanthio and Evzonoi revealed statistically significant downward trends. Comparing the results of the three trend tests (Table 8), it can be noted that the all stations for all time periods of study, the trends show the same sign behavior with a few exceptions. The trend slope of time series that were found statistically significant trends is presented in Figure 8. As it can be observed the maximum positive slope value is 1.99 $\mathrm{mm} / \mathrm{month}$ at Skra station in December while the maximum negative slope value is $1.00 \mathrm{~mm} / \mathrm{month}$ at Ano Theodoraki station in May which is a crucial month for irrigation purposes.

Table 8. Total results of the sign of precipitation trend in the study area.

\begin{tabular}{cccccccccccccc}
\hline \multicolumn{11}{c}{ Mann-Kendall-Sen's T-Spearman (5\% S. L) } \\
\hline \multicolumn{11}{c}{ Nov. Dojran } & \multicolumn{4}{c}{ Ano Theodoraki } & \multicolumn{1}{c}{ Metaxochori } & \multicolumn{1}{c}{ Kilkis } \\
\hline Total & M-K & Sen's & Spearman & M-K & Sen's & Spearman & M-K & Sen's & Spearman & M-K & Sen's & Spearman \\
Precipitation & Z & T & $\rho$ & Z & T & $\rho$ & Z & T & $\rho$ & Z & T & $\rho$ \\
\hline Annual & + & + & + & - & - & - & - & - & - & $-*$ & $-*$ & $-*$ \\
\hline
\end{tabular}


Continued

\begin{tabular}{|c|c|c|c|c|c|c|c|c|c|c|c|c|}
\hline Winter & + & + & + & + & + & + & - & - & - & - & - & - \\
\hline Spring & - & - & - & - & - & - & - & - & - & - & - & - \\
\hline Summer & - & - & - & - & - & - & - & - & - & $-*$ & $-*$ & $-*$ \\
\hline Autumn & + & + & + & + & + & + & - & - & - & - & - & - \\
\hline Irrig. Period & + & + & + & - & - & - & - & - & - & - & - & - \\
\hline October & + & + & + & + & + & + & + & - & - & - & - & - \\
\hline November & - & - & - & - & - & - & - & - & - & - & - & - \\
\hline December & + & + & + & + & + & + & + & + & + & + & + & + \\
\hline January & + & + & + & + & + & + & - & - & - & - & - & - \\
\hline February & - & - & - & - & - & - & - & - & - & - & - & - \\
\hline March & - & - & - & - & - & - & - & - & - & - & - & - \\
\hline April & + & + & + & - & - & - & + & + & + & - & - & - \\
\hline May & - & - & - & $-*$ & $-*$ & $-*$ & - & - & - & - & - & - \\
\hline June & + & + & + & + & + & + & - & - & - & - & - & - \\
\hline July & - & - & - & - & + & + & - & - & - & - & - & - \\
\hline August & - & - & - & - & - & - & - & - & - & $-*$ & $-*$ & $-*$ \\
\hline \multirow[t]{2}{*}{ September } & + & + & + & + & + & + & + & + & + & + & + & + \\
\hline & \multicolumn{3}{|c|}{ Melanthio } & \multicolumn{3}{|c|}{ Anthofito } & \multicolumn{3}{|c|}{ Megali Sterna } & \multicolumn{3}{|c|}{ EVzonoi } \\
\hline $\begin{array}{c}\text { Total } \\
\text { Precipitation }\end{array}$ & M-K Z & $\begin{array}{l}\text { Sen's } \\
\mathrm{T}\end{array}$ & $\begin{array}{c}\text { Spearman } \\
\rho\end{array}$ & M-K Z & $\begin{array}{l}\text { Sen's } \\
\mathrm{T}\end{array}$ & $\begin{array}{c}\text { Spearman } \\
\rho\end{array}$ & M-K Z & $\begin{array}{l}\text { Sen's } \\
\mathrm{T}\end{array}$ & $\begin{array}{c}\text { Spearman } \\
\rho\end{array}$ & M-K Z & $\begin{array}{c}\text { Sen's } \\
\mathrm{T}\end{array}$ & $\begin{array}{c}\text { Spearman } \\
\rho\end{array}$ \\
\hline Annual & + & + & + & - & - & - & - & - & - & - & + & + \\
\hline Winter & + & + & + & + & + & + & - & + & + & + & + & + \\
\hline Spring & + & + & + & - & - & - & - & - & - & - & - & - \\
\hline Summer & + & + & + & - & - & - & + & + & + & - & - & - \\
\hline Autumn & + & + & + & - & - & - & + & + & + & - & - & - \\
\hline Irrig. Period & + & + & + & - & - & - & + & + & + & + & + & + \\
\hline October & + & + & + & 0 & - & - & - & - & - & + & + & + \\
\hline November & + & + & + & $-*$ & $-*$ & $-*$ & - & - & - & - & - & - \\
\hline December & + & + & + & + & - & - & + & + & + & + & + & + \\
\hline January & + & + & + & + & + & + & + & + & + & + & + & + \\
\hline February & - & - & - & - & - & - & - & - & - & - & - & - \\
\hline March & - & - & - & - & - & - & - & - & - & - & - & - \\
\hline April & + & + & + & + & + & + & + & + & + & - & - & - \\
\hline May & + & + & + & - & - & - & - & - & - & - & - & - \\
\hline June & + & + & + & - & - & - & 0 & + & + & 0 & - & - \\
\hline July & + & + & + & - & - & - & + & + & + & - & - & - \\
\hline August & + & + & + & - & - & - & + & + & + & - & - & - \\
\hline \multirow[t]{2}{*}{ September } & $+^{*}$ & $+^{*}$ & $+^{*}$ & + & + & + & $+^{*}$ & $+^{*}$ & $+^{*}$ & $+^{*}$ & $+^{*}$ & $+^{*}$ \\
\hline & \multicolumn{3}{|c|}{ Polikastro } & \multicolumn{3}{|c|}{ Evropos } & \multicolumn{3}{|c|}{ Goumenissa } & \multicolumn{3}{|c|}{$S k r a$} \\
\hline $\begin{array}{c}\text { Total } \\
\text { Precipitation }\end{array}$ & M-K Z & $\begin{array}{l}\text { Sen's } \\
\mathrm{T}\end{array}$ & $\begin{array}{c}\text { Spearman } \\
\rho\end{array}$ & M-K Z & $\begin{array}{c}\text { Sen's } \\
\mathrm{T}\end{array}$ & $\begin{array}{c}\text { Spearman } \\
\rho\end{array}$ & $\mathrm{M}-\mathrm{K} \mathrm{Z}$ & $\begin{array}{l}\text { Sen's } \\
\mathrm{T}\end{array}$ & $\begin{array}{c}\text { Spearman } \\
\rho\end{array}$ & M-K Z & $\begin{array}{c}\text { Sen's } \\
\mathrm{T}\end{array}$ & $\begin{array}{c}\text { Spearman } \\
\rho\end{array}$ \\
\hline Annual & - & - & - & - & - & - & + & + & + & + & + & + \\
\hline Winter & - & - & - & + & + & + & + & + & + & + & + & + \\
\hline
\end{tabular}




\section{Continued}

\begin{tabular}{|c|c|c|c|c|c|c|c|c|c|c|c|c|}
\hline Spring & - & - & - & - & - & - & - & - & - & - & - & - \\
\hline Summer & - & - & - & - & - & - & - & - & - & + & + & + \\
\hline Autumn & - & - & - & + & + & + & + & + & + & + & + & + \\
\hline Irrig. Period & - & - & - & - & - & - & - & - & - & + & + & + \\
\hline October & - & - & - & + & + & + & - & - & - & - & - & - \\
\hline November & - & - & - & - & - & - & - & - & - & + & + & + \\
\hline December & + & + & + & + & + & + & + & + & + & $+^{*}$ & $+^{*}$ & $+^{*}$ \\
\hline January & - & - & - & + & + & + & 0 & + & + & + & + & + \\
\hline February & - & - & - & + & + & + & - & - & - & - & - & - \\
\hline March & - & - & - & - & - & - & - & - & - & - & - & - \\
\hline April & 0 & + & 0 & - & - & - & + & + & + & + & + & + \\
\hline May & + & + & + & - & - & - & - & - & - & - & - & - \\
\hline June & - & - & - & - & - & - & - & - & - & + & + & + \\
\hline July & - & - & - & - & - & - & + & + & + & + & + & + \\
\hline August & - & - & - & $-*$ & $-*$ & $-*$ & - & - & - & - & - & - \\
\hline September & - & - & - & + & + & + & + & + & + & - & - & - \\
\hline
\end{tabular}

*Statistically significance at the $5 \%$ level of significance.
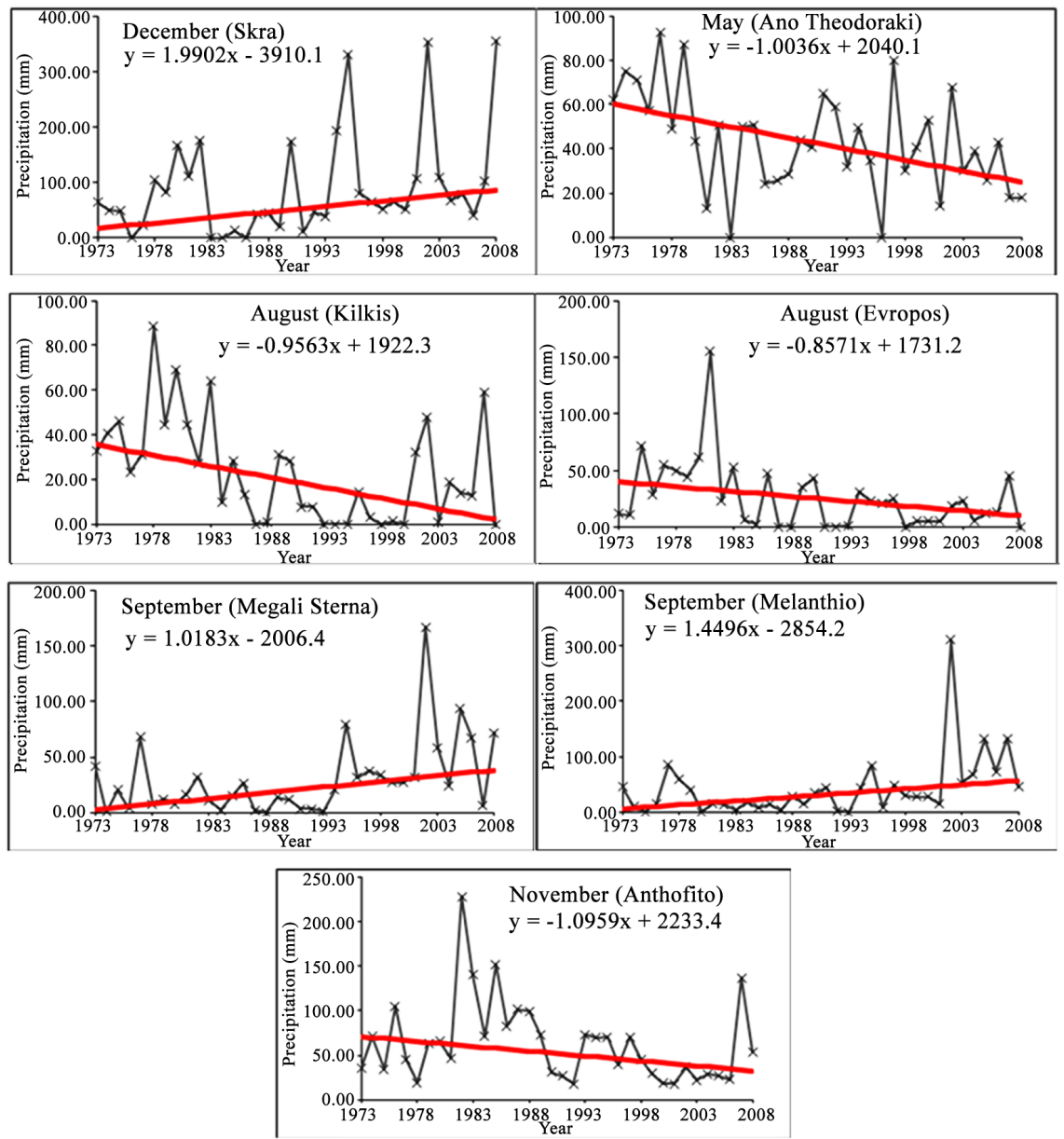

Figure 8. Monthly statistically significant trends at station level in the study area (5\% level of significance). 


\subsection{Regional Trend Analysis}

The investigation of precipitation trends in the area was performed by the Regional Average Mann-Kendall (RAMK) test. Furthermore, in order to assess the field significance, the spatial RAMK trend test was evaluated with the Bootstrap Empirical Cumulative Distribution (BECD). The bootstrap RAMK test was elaborated in two versions: with and without preserving cross-correlation.

As it concerns the RAMK test, the region showed a downward trend of precipitation during the annual period which was not found to be statistically significant. Same trend sign, but weaker has appeared during the irrigation period. Statistically significant at $5 \%$ and $10 \%$ significance level were estimated the trends at regional level in the seasons of spring and summer respectively (Table 9). The winter and autumn seasons were characterized as seasons with upward trend, not statistically significant according to the results of Table 9.

In the monthly observations, the spatial trends showed a larger statistical interest, as the $58.3 \%$ of them was determined to be statistically significant at a significance level of $5 \%$ (Table 9). In detail, the months of November, February, March, May and August have downward trends at 5\% significance level. Contrary, the months September and December showed significant upward trends and slopes at a significance level of $5 \%$.

The analysis of trends in the region, in order to assess the field significance, is investigated using RAMK Bootstrap test without (RAMK-B1) and with (RAMK-B2) preserving the cross correlation. For each time period of observation, 4.000 random repetitions were conducted and 4.000 values of $S$ statistic were calculated. In Table 9, the results of the two bootstrap RAMK tests are presented. The effect of spatial correlation at the level of significance of $5 \%$ can be clearly seen by comparing the results of the trend of the two tests (Figure 9), while the BECD's without and with cross correlation is shown in Figure 10.

Table 9. RAMK test results and RAMK-B $(1,2)$ at 5\% (bold) and $10 \%$ (italics) level of significance respectively.

\begin{tabular}{|c|c|c|c|c|c|c|c|c|}
\hline \multirow[t]{2}{*}{ Field Significance } & \multicolumn{4}{|c|}{ RAMK test } & \multicolumn{2}{|c|}{$\begin{array}{l}\text { RAMK-B1 test } \\
\text { (without cross correlation) }\end{array}$} & \multicolumn{2}{|c|}{$\begin{array}{c}\text { RAMK-B2 test } \\
\text { (with cross correlation) }\end{array}$} \\
\hline & $S$ av. & $\mathbf{P}_{\text {obs }}$ & $P_{f}$ & $\mathrm{Z}$ & $\mathbf{P}_{\mathrm{obs}}$ & Pf & $P_{\text {obs }}$ & $P_{f}$ \\
\hline Annual & -33.6 & 0.113 & 0.113 & -1.59 & 0.058 & 0.058 & 0.181 & 0.181 \\
\hline Irrig. & -20.4 & 0.337 & 0.337 & -0.96 & 0.177 & 0.177 & 0.327 & 0.327 \\
\hline Winter & 26.4 & 0.214 & 0.214 & 1.24 & 0.898 & 0.102 & 0.689 & 0.311 \\
\hline Spring & -60.8 & 0.004 & 0.004 & -2.87 & 0.002 & 0.002 & 0.083 & 0.083 \\
\hline Summer & -35.6 & 0.094 & 0.094 & -1.68 & 0.048 & 0.048 & 0.260 & 0.260 \\
\hline Autumn & 8.83 & 0.680 & 0.320 & 0.41 & 0.676 & 0.324 & 0.586 & 0.414 \\
\hline Oct. & 4.66 & 0.829 & 0.171 & 0.22 & 0.570 & 0.430 & 0.534 & 0.466 \\
\hline Nov. & -73.1 & 0.001 & 0.001 & -3.45 & 0.001 & 0.001 & 0.096 & 0.096 \\
\hline Dec. & 64.5 & 0.002 & 0.002 & 3.04 & 1.000 & 0.000 & 0.891 & 0.109 \\
\hline Jan. & 17.3 & 0.414 & 0.414 & 0.82 & 0.790 & 0.210 & 0.677 & 0.323 \\
\hline
\end{tabular}




\section{Continued}

\begin{tabular}{|c|c|c|c|c|c|c|c|c|}
\hline Feb. & -64.6 & 0.002 & 0.002 & -3.05 & 0.002 & 0.002 & 0.109 & 0.109 \\
\hline March & -76.9 & 0.000 & 0.000 & -3.63 & 0.000 & 0.000 & 0.060 & 0.060 \\
\hline Apr. & 5.7 & 0.792 & 0.208 & 0.26 & 0.624 & 0.376 & 0.529 & 0.471 \\
\hline May & -57.7 & 0.005 & 0.005 & -2.79 & 0.004 & 0.004 & 0.112 & 0.112 \\
\hline June & -2.9 & 0.894 & 0.106 & -0.13 & 0.446 & 0.446 & 0.466 & 0.466 \\
\hline July & -22 & 0.300 & 0.300 & -1.04 & 0.153 & 0.153 & 0.338 & 0.338 \\
\hline Aug. & -60.1 & 0.005 & 0.005 & -2.84 & 0.001 & 0.001 & 0.091 & 0.091 \\
\hline Sept. & 87.2 & 0.000 & 0.000 & 4.11 & 1.000 & 0.000 & 0.963 & 0.037 \\
\hline
\end{tabular}
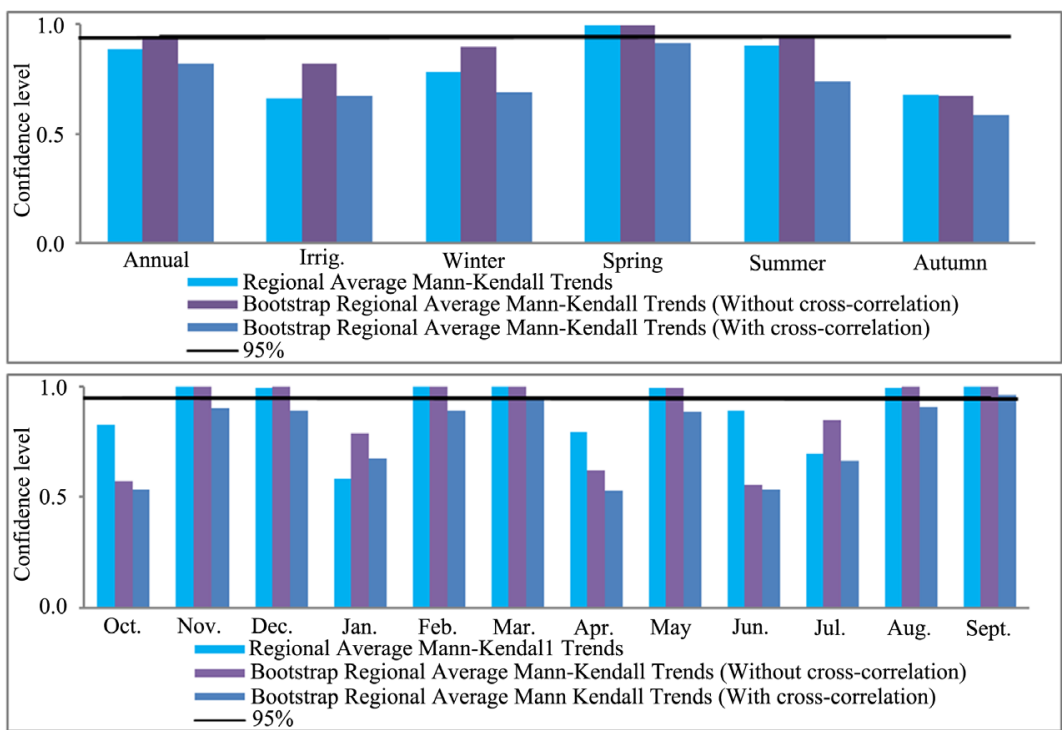

Figure 9. Charts comparing RAMK test and RAMK-B $(1,2)$ tests at regional level for time study periods.

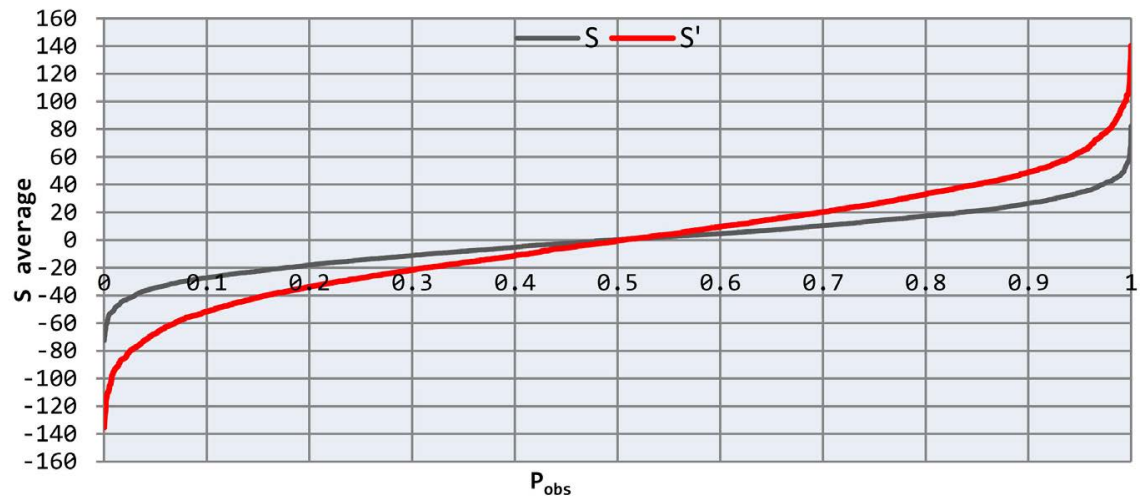

Figure 10. The annual bootstrap empirical cdf curve for the region with the effect of cross correlation (S') and without (S).

In the monthly observations, the spatial trends showed a larger statistical interest, as the $58.3 \%$ of them was determined to be statistically significant at a significance level of 5\% (Table 9). In detail, the months of November, February, 
March, May and August have downward trends at 5\% significance level. Contrary, the months September and December showed significant upward trends and slopes at a significance level of $5 \%$.

The analysis of trends in the region, in order to assess the field significance, is investigated using RAMK Bootstrap test without (RAMK-B1) and with (RAMK-B2) preserving the cross correlation. For each time period of observation, 4.000 random repetitions were conducted and 4.000 values of $S$ statistic were calculated. In Table 9, the results of the two bootstrap RAMK tests are presented. The effect of spatial correlation at the level of significance of $5 \%$ can be clearly seen by comparing the results of the trend of the two tests (Figure 9), while the BECD's without and with cross correlation is shown in Figure 10.

As illustrated in Figure 9, the negative trend in the region during the annual period appears statistically significant at the level of significance of 10\% (Table 9) only with RAMK-B1 test, fact which was not verified with the corresponding tests RAMK and RAMK-B2 respectively. This reinforces the hypothesis of cross correlation existence in the historical time series whose results converge with those of test RAMK-B2. The annual bootstrap empirical cdf curves with and without cross correlation show the effect of cross correlation in the identification of field significance (Figure 10).

The results of spatial trends in precipitation during the periods of winter, autumn and irrigation showed no statistically significant trend for all tests. However, the season of spring was characterized by statistically significant downward trend (Table 9 and Figure 9) at significance level of 5\% with the tests RAMK and RAMK-B1, which was verified by RAMK-B2 but at $10 \%$ significance level. Finally, during the season of summer the spatial test RAMK-B1 detected trends at significance level of 5\% while test RAMK at a significance level of $10 \%$.

In monthly observations, the RAMK-B2 has also identified fewer trends compared to RAMK-B1 (Figure 9). Similar, regarding the effect of the cross correlation with bootstrap tests, were the results [32] in the analysis of the minimum annual, mean annual and maximum annual daily flow in Canada.

In this study, both RAMK-B tests estimated negative precipitation trends in the months November, August and March which were statistically significant at a significance level of $5 \%$ and $10 \%$ for RAMK-B1 and RAMK-B2 tests respectively. The most important upward trend in the region was identified by both tests in September at significance level 5\%. Also, an upward trend is detected in December with RAMK-B1 test while it was not verified with RAMK-B2 test. It is noted that for both negative and positive spatial trends identified by RAMK-B1 test were also found by the RAMK test of the historical time series. In most cases the RAMK-B2 test identified fewer field significances of trend than the corresponding RAMK-B1, with the exception of month January and the irrigation period.

\section{Conclusions}

At station level, the results produced by Mann-Kendall test, Sen's T test, Sen's 
estimate of slope test and Spearman test were highly consistent for all time scales. The precipitation trend according to the tests mentioned above appeared in most cases downward during the annual analysis and statistically significant at $5 \%$ level of significance only in one station. In seasonal analysis, statistically significant (5\% s.l.) was detected also only at one station with a downward precipitation trend during the summer period. Comparing the results at a monthly scale in all stations, several statistically significant trends were found at a few numbers of stations. The station Nov. Doiran on the part of F.Y.R.O.M. did not show at station level a statistically significant negative or positive precipitation trend at any of the recording time periods, except for mild negative and positive trends and inclinations respectively. Greater mild negative non-statistically significant trend occurred during spring. This may signal the fact that there have not been long periods of minimum water availability in Lake Doirani's basin through precipitation. Thus, variables such as wind temperature and velocity may have contributed to increased evaporation and reduced soil moisture. As a result, significant droughts occur in the lake, especially from 1973 to 2002 [34].

At a regional level, RAMK-B2 test revealed statistically significant positive trends in precipitation at 5\% significance level only during September. In addition, statistically significant negative spatial trends were observed in the season of spring and at $10 \%$ significance level for the months November, March and August. Instead, the RAMK-B1 test estimated negative spatial trends statistically significant at a significance level of 5\% for the seasons of spring and summer as well as for the months of November, February, March, May and August. Also, a negative trend was identified for the annual period at significance level of $10 \%$. Positive spatial trends at 5\% significance level were observed during December (RAMK, RAMK-B1) and September with all spatial tests, respectively. Overall, the trend of precipitation was statistically significant at a level of $10 \%$ only with RAMK-1 control during the annual period while 5\% in spring [35] and summer [34] in RAMK and RAMK-1 control respectively. For all examined time periods, the RAMK test showed statistically significant spatial trends at significance level of $5 \%$ at a rate of $44.4 \%(8 / 18)$, the RAMK-B1 test at a rate of $50 \%(9 / 18)$, while the RAMK-B2 test at a rate of 5.5\% (1/18). Extending the significance level to $10 \%$, the RAMK test showed statistically significant spatial trends at a rate of $50 \%$ (9/18), the RAMK-B1 test at a rate of $55.5 \%$ (10/18), while the RAMK-B2 test at a rate of $\% 27.7(5 / 18)$. Comparing the results of the two bootstrap tests, it is highlighted that field significance of trends in the study area is influenced by the effect of cross-correlation between the stations.

Closing, the spatial inspections, with the exception of the RAMK-2 test, showed a wealth of statistically significant and less statistically significant trends, which is confirmed by other researchers too on precipitation trends in the surrounding area and in Greece in general [36] [37].

\section{Acknowledgements}

I would like to thank the local Department of Land Reclamation of Kilkis (Minis- 
try of Environment, Energy and Climate Change) and the Greek Biotope/Wetland Centre for the provision of precipitation data. In conclusion, i would like to thank my mother Margaritidou Anastasia for her help both in the collection of data and in the recording, as well as in the psychological support during the whole process of this research.

\section{Conflicts of Interest}

The author declares no conflicts of interest regarding the publication of this paper.

\section{References}

[1] Gemmer, M., Becker, S. and Jiang, T. (2004) Observed Monthly Precipitation Trends in China 1951-2002. Theoretical and Applied Climatology, 77, 39-45. https://doi.org/10.1007/s00704-003-0018-3

[2] Parry, M.L., Canziani, O., Palutikof, J., Van Der Linden, P. and Hanson, C. (2007) IPCC Climate Change 2007: Impacts, Adaptation and Vulnerability. Contribution of Working Group II to the Fourth Assessment Report of the Intergovernmental Panel on Climate Change. Cambridge University Press, Cambridge, UK, 976.

[3] Xu, L., Zhou, H., Du, L., Yao, H. and Wang, H. (2015) Precipitation Trends and Variability from 1950 to 2000 in Arid Lands of Central Asia. Journal of Arid Land, 7, 514-526. https://doi.org/10.1007/s40333-015-0045-9

[4] Hu, Y., Wang, S., Song, X. and Wang, J. (2017) Precipitation Changes in the Mid-Latitudes of the Chinese Mainland during 1960-2014. Journal of Arid Land, 9, 924-937. https://doi.org/10.1007/s40333-017-0105-4

[5] Wu, Y., Bake, B., Zhang, J. and Rasulov, H. (2015) Spatio-Temporal Patterns of Drought in North Xinjiang, China, 1961-2012 Based on Meteorological Drought Index. Journal of Arid Land, 7, 527-543. https://doi.org/10.1007/s40333-015-0125-x

[6] Yue, S. and Wang, C.Y. (2002) Regional Streamflow Trend Detection with Consideration of Both Temporal and Spatial Correlation. International Journal of Climatology, 22, 933-946. https://doi.org/10.1002/joc.781

[7] Buffoni, L., Maugeri, M. and Nanni, T. (1999) Precipitation in Italy from 1833 to 1996. Theoretical and Applied Climatology, 63, 33-40. https://doi.org/10.1007/s007040050089

[8] Piccarreta, M., Capolongo, D. and Boenzi, F. (2004) Trend Analysis of Precipitation and Drought in Basilicata from 1923 to 2000 within a Southern Italy Context. International Journal of Climatology, 24, 907-922. https://doi.org/10.1002/joc.1038

[9] Partal, T. and Kahya, E. (2006) Trend Analysis in Turkish Precipitation Data. Hydrological Processes, 20, 2011-2026. https://doi.org/10.1002/hyp.5993

[10] Cannarozzo, M., Noto, L.V. and Viola, F. (2006) Spatial Distribution of Rainfall Trends in Sicily (1921-2000). Physics and Chemistry of the Earth, Parts $A / B / C, 31$, 1201-1211. https://doi.org/10.1016/j.pce.2006.03.022

[11] Smadi, M.M. and Zghoul, A. (2006) A Sudden Change in Rainfall Characteristics in Amman, Jordan during the Mid1950s. American Journal of Environmental Sciences, 2, 84-91.

[12] De Lima, M.I.P., Marques, A.C., De Lima, J.L.M.P. and Coelho, M.F.E.S. (2007) Precipitation Trends in Mainland Portugal in the Period 1941-2000. In: Lobo Ferreira, J.P. and Viera, J.M.P., Eds., Water in Celtic Countries: Quantity, Quality and 
Climate Variability, International Association of Hydrological Sciences, Wallingford, 94-102.

[13] Chaouche, K., Neppel, L., Dieulin, C., Pujol, N., Ladouche, B., Martin, E. and Caballero, Y. (2010) Analyses of Precipitation, Temperature and Evapotranspiration in a French Mediterranean Region in the Context of Climate Change. Comptes Rendus Geoscience, 342, 234-243. https://doi.org/10.1016/j.crte.2010.02.001

[14] Luna, M.Y., Guijarro, J.A. and López, J.A. (2012) A Monthly Precipitation Database for Spain (1851-2008): Reconstruction, Homogeneity and Trends. Advances in Science and Research, 8, 1-4. https://doi.org/10.5194/asr-8-1-2012

[15] Dalezios, N.R. and Bartzokas, A. (1995) Daily Precipitation Variability in Semiarid Agricultural Regions in Macedonia, Greece. Hydrological Sciences Journal, 40, 569-585. https://doi.org/10.1080/02626669509491445

[16] Kambezidis, H.D., Larissi, I.K., Nastos, P.T. and Paliatsos, A.G. (2010) Spatial Variability and Trends of the Rain Intensity over Greece. Advances in Geosciences, 26, 65-69. https://doi.org/10.5194/adgeo-26-65-2010

[17] Karpouzos, D.K., Kavalieratou, S. and Babajimopoulos, C. (2010) Trend Analysis of Precipitation Data in Pieria Region (Greece). European Water, 30, 31-40.

[18] Nastos, P.T. and Zerefos, C.S. (2010) Climate Change and Precipitation in Greece. Hellenic Journal of Geosciences, 45, 185-192.

[19] Myronidis, D., Stathis, D., Ioannou, K. and Fotakis, D. (2012) An Integration of Statistics Temporal Methods to Track the Effect of Drought in a Shallow Mediterranean Lake. Water Resources Management, 26, 4587-4605.

https://doi.org/10.1007/s11269-012-0169-Z

[20] Matalas, N.C. and Jacobs, B. (1964) A Correlation Procedure for Augmenting Hydrologic Data. US Government Printing Office, 434, 1-13.

https://doi.org/10.3133/pp434E

[21] Margaritidis, K.A and Karpouzos, K.D. (2015) Homogeneity of Rainfall Time Series Analysis in the Wider Area of Doiran. Proceedings of the $9^{\text {th }}$ Panhellenic Conference of Agricultural Engineering, Thessaloniki, 8-9 October 2015, 123-132.

[22] Rai, R.K., Upadhyay, A. and Ojha, C.S.P. (2010) Temporal Variability of Climatic Parameters of Yamuna River Basin: Spatial Analysis of Persistence, Trend and Periodicity. The Open Hydrology Journal, 4, 184-210. https://doi.org/10.2174/1874378101004010184

[23] Yue, S., Pilon, P. and Cavadias, G. (2002) Power of the Mann-Kendall and Spearman's Rho Tests for Detecting Monotonic Trends in Hydrological Series. Journal of Hydrology, 259, 254-271. https://doi.org/10.1016/S0022-1694(01)00594-7

[24] Eymen, A. and Köylü, Ü. (2018) Seasonal Trend Analysis and ARIMA Modeling of Relative Humidity and Wind Speed Time Series around Yamula Dam. Meteorology and Atmospheric Physics, 131, 601-612. https://doi.org/10.1007/s00703-018-0591-8

[25] Sen, P.K. (1968) On a Class of Aligned Rank Order Tests in Two-Way Layouts. The Annals of Mathematical Statistics, 39, 1115-1124. https://doi.org/10.1214/aoms/1177698236

[26] Sen, P.K. (1968) Estimates of the Regression Coefficient Based on Kendall's Tau. Journal of the American Statistical Association, 63, 1379-1389. https://doi.org/10.1080/01621459.1968.10480934

[27] Van Belle, G. and Hughes, J.P. (1984) Nonparametric Tests for Trend in Water Quality. Water Resources Research, 20, 127-136. https://doi.org/10.1029/WR020i001p00127 
[28] Douglas, E.M., Vogel, R.M. and Kroll, C.N. (2000) Trends in Floods and Low Flows in the United States: Impact of Spatial Correlation. Journal of Hydrology, 240, 90-105. https://doi.org/10.1016/S0022-1694(00)00336-X

[29] Helsel, D.R. and Frans, L.M. (2006) Regional Kendall Test for Trend. Environmental Science and Technology, 40, 4066-4073. https://doi.org/10.1021/es051650b

[30] Palizdan, N., Falamarzi, Y., Huang, Y.F., Lee, T.S. and Ghazali, A.H. (2014) Regional Precipitation Trend Analysis at the Langat River Basin, Selangor, Malaysia. Theoretical and Applied Climatology, 117, 589-606. https://doi.org/10.1007/s00704-013-1026-6

[31] Yue, S. and Hashino, M. (2003) Long Term Trends of Annual and Monthly Precipitation in Japan. JAWRA Journal of the American Water Resources Association, 39, 587-596. https://doi.org/10.1111/j.1752-1688.2003.tb03677.x

[32] Yue, S., Pilon, P. and Phinney, B.O.B. (2003) Canadian Streamflow Trend Detection: Impacts of Serial and Cross-Correlation. Hydrological Sciences Journal, 48, 51-63. https://doi.org/10.1623/hysj.48.1.51.43478

[33] Mann, H.B. (1945) Nonparametric Tests against Trend. Econometrica, 13, 245-259. https://doi.org/10.2307/1907187

[34] Myronidis, D. (2010) Research of the Causes in the Drop of Lake Doirani's Water Level (Greece) and Elaboration of a Pilot Action Plan for Its Restoration, Final Report. State Scholarship Foundation, Greece, 79.

[35] Ruixia, G., Clara, D., Laurent, T. and Flavio, L. (2019) Human Influence on Winter Precipitation Trends (1921-2015) over North America and Eurasia. Revealed by Dynamical Adjustment. Geophysical Research Letters, 46, 3426-3434. https://doi.org/10.1029/2018GL081316

[36] Mavromatis, T. and Stathis D. (2011) Response of the Water Balance in Greece to Temperature and Precipitation Trends. Theoretical and Applied Climatology, 104, 13-24. https://doi.org/10.1007/s00704-010-0320-9

[37] Feidas, X., Noulopoulou, C., Makrogiannis, T. and Bora-Senta, E. (2007) Trend Analysis of Precipitation Time Series in Greece and Their Relationship with Circulation Using Surface and Satellite Data: 1955-2001. Theoretical and Applied Climatology, 87, 155-177. https://doi.org/10.1007/s00704-006-0200-5 